\title{
Severe haemolysis after percutaneous closure of a ductus arteriosus (arterial duct)
}

\author{
E J LADUSANS, * I MURDOCH, * J FRANCIOSI $\dagger$
}

From the Departments of *Paediatric Cardiology and †Cardiothoracic Surgery, Guy's Hospital London

SUMMARY Severe mechanical haemolysis occurred after transcatheter occlusion of a ductus arteriosus (arterial duct) by a Rashkind double umbrella prosthesis. Surgical removal of the device and ligation of the duct were required before haemolysis was abolished.

Transcatheter occlusion of the ductus arteriosus (arterial duct) was first reported by Porstmann et al, who used a wire and plug technique. ${ }^{1}$ Subsequently Rashkind et al developed a double umbrella prosthesis $^{2}$ and showed that this could be used successfully to close the arterial duct. ${ }^{3}$ Complications described from this procedure include arterial or pulmonary embolisation of the device and residual duct leaks. ${ }^{34}$ We describe a hitherto unreported hazard-that of severe haemolysis after insertion of the Rashkind occluder.

\section{Case report}

A symptom free two and a half year old girl was found to have a heart murmur on a routine examination. A continuous murmur was heard below the left clavicle and echocardiography confirmed an arterial duct and normal intracardiac structure. The parents agreed to have the defect closed by percutaneous technique. This was carried out by the method of Bash and Mullins. ${ }^{5}$ A preliminary aortogram through a retrograde arterial catheter defined the anatomy of the duct and showed that it measured $3 \mathrm{~mm}$ at the narrowest point (fig 1). An 0.038 exchange guide wire (William Cook Europe) was passed through a venous catheter into the descending aorta via the duct. An 8 French Mullins transseptal sheath (William Cook Europe) was then passed over the guide wire into the descending aorta. A $12 \mathrm{~mm}$ Rashkind double umbrella prosthesis (USCI, Billerica, MA) was passed through a Rashkind delivery catheter into the Mullins sheath. The device was advanced so that the distal umbrella opened in the aorta. The whole system, including the sheath, was then slowly pulled back until the distal umbrella was well seated in the

Requests for reprints to Dr E J Ladusans, Department of Paediatric Cardiology, Guy's Hospital, St Thomas Street, London SE1 9RT. aortic end of the duct. The sheath was then retracted further so that the proximal umbrella could spring 9 open and secure the device at the pulmonary end of $\overrightarrow{ }$ the duct. The device was released and we noted that $\subsetneq$ the prosthesis had been pulled a little too far towards $\Phi$ the pulmonary end of the duct (fig $2 a$ ). A repeat $\vec{\oplus}$ aortogram showed that there was a considerable leak $\mathbb{\infty}$ through the duct around the device (fig 2b). The apparent increase in size of the duct was caused by changes in magnification and true dilatation of the duct by the passage of the 8 French transseptal sheath and delivery catheter.

Eighteen hours after insertion of the prosthesis she began to pass heavily bloodstained urine and was jaundiced. Microscopical examination of the urine showed haemoglobin but no red blood cells. The blood haemoglobin fell from $110 \mathrm{~g} / 1$ pre-catheter to

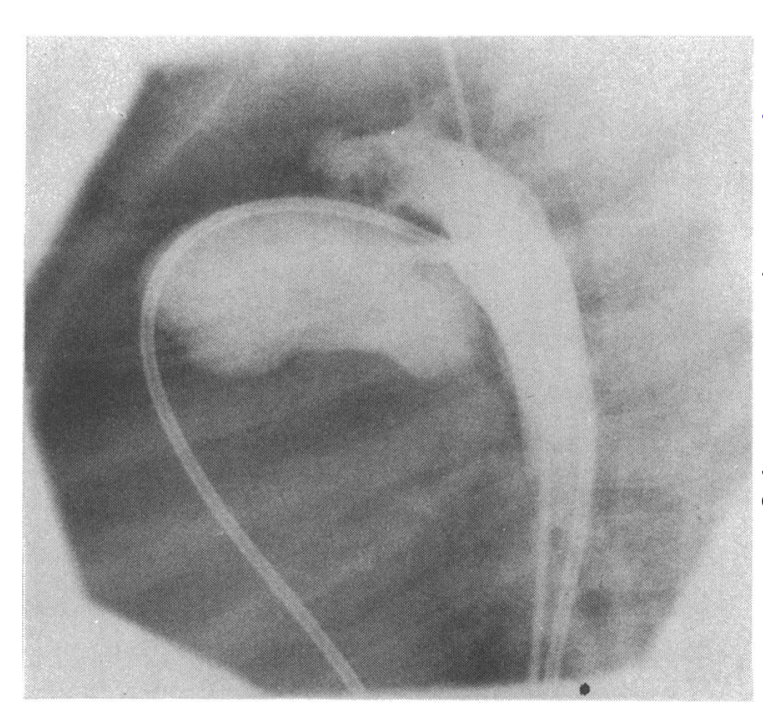

Fig 1 Initial aortogram showing arterial duct. 


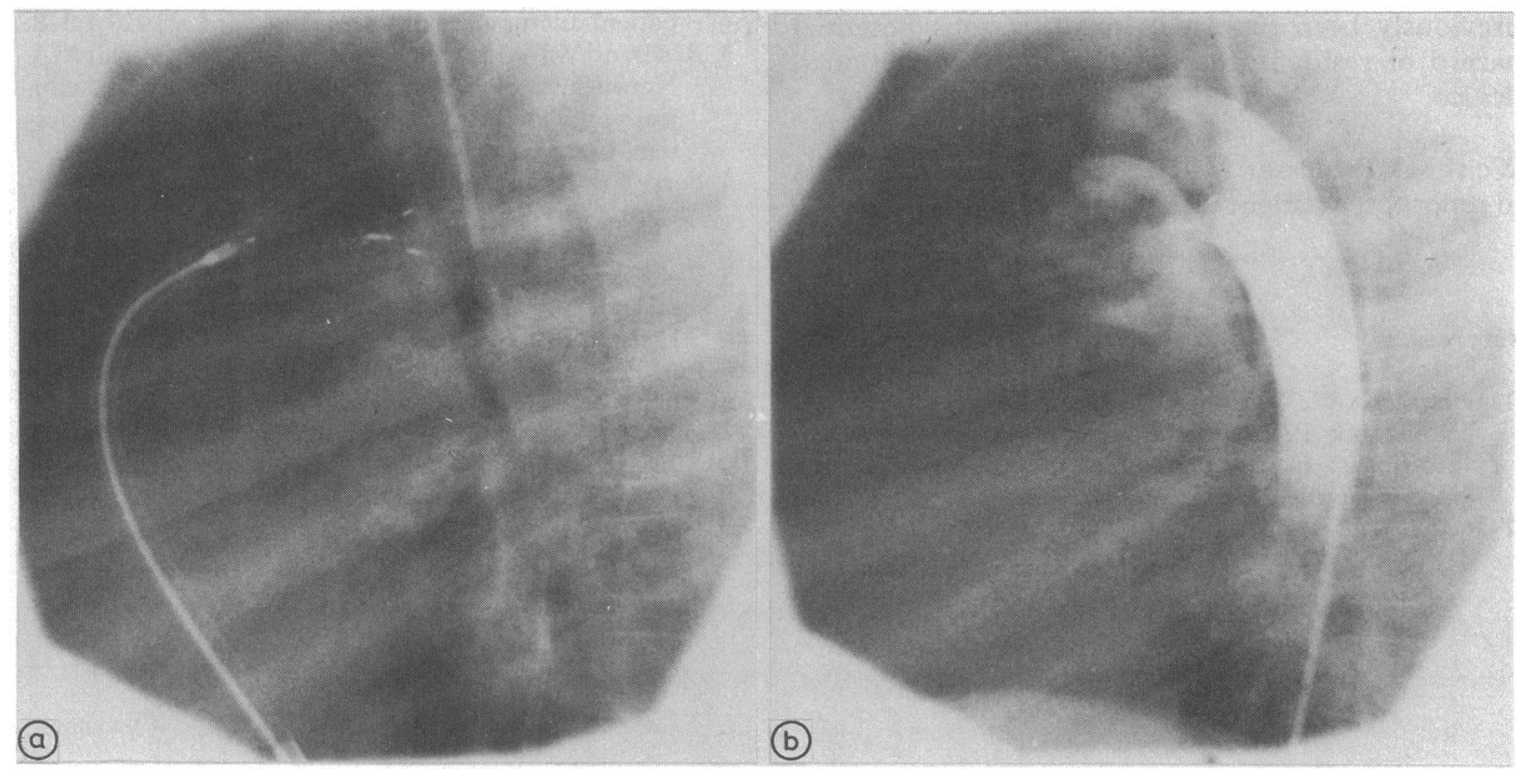

Fig 2 (a) Lateral radiograph after release of the device. The proximal umbrella (faintly radio-opaque prongs) was positioned too far into the pulmonary artery. (b) Aortogram after implantation of the device. Residual flow was seen through the arterial duct and around the device.

$79 \mathrm{~g} / \mathrm{l}$. There was a progressive reticulocytosis and a blood film showed evidence of red cell fragmentation. Blood cultures were negative.

A repeat echocardiogram showed that the proximal umbrella was situated further into the pulmonary artery than is usual and there was clot around the umbrella. Doppler examination confirmed a residual leak through the duct. The haemolysis was initially treated conservatively with blood transfusions to correct her anaemia. After 72 hours there was no decrease in red cell destruction and blood haemoglobin had fallen again to $74 \mathrm{~g} / \mathrm{l}$. She was referred for urgent surgical removal of the device and duct ligation. At operation the main pulmonary artery was cross clamped and the descending aorta side clamped at the origin of the arterial duct. The duct was incised longitudinally and the occluder retrieved. The prosthesis had not been damaged and there was no evidence of infection. The duct was then oversewn and ligated with linen sutures. Postoperative recovery was uneventful with no further haemolysis and the blood haemoglobin concentrations was maintained at $130 \mathrm{~g} / \mathrm{l}$.

\section{Discussion}

The Rashkind occluder consists of two discs mounted on two opposing three arm spring assemblies. The whole device resembles two connected umbrellas. ${ }^{6}$ Each disc is constructed from open-pore polyurethane foam and though initially blood can leak through this mesh, animal experiments have shown that the discs rapidly become endothelialised. They are eventually covered with tissue and incorporated into the arterial walls. ${ }^{3} \mathrm{We}$ postulate that in our patient severe haemolysis occurred because the prosthesis was implanted with the proximal umbrella too far into the pulmonary artery. This resulted in a residual leak through the duct and around the device with a high velocity jet of blood directed on to the mesh of the proximal disc and consequent damage to the red cells.

Rashkind et al reported an initial experience of this device in 146 patients. ${ }^{3}$ There was systemic or pulmonary embolisation of the device immediately after its release in $13 \%$ of patients. Ten per cent of patients had evidence of residual flow despite successful implantation of the occluder. Perry et al found similar results in 28 patients-with four embolisations and four patients with considerable residual leak. Dyck et al treated 40 patients with the duct occluder. ${ }^{7}$ There were two embolisations and $21 \%$ of patients had a residual leak. One patient developed staphylococcal septicaemia after insertion of the device and probable prosthetic endartritis. MJ Tynan at Guy's Hospital has experience of 70 implantations. Two devices embolised and there was residual flow in the duct in four patients (personal communication). To our knowledge severe haemolysis after insertion of a Rashkind prosthesis has not 
previously been reported; it is a serious potential hazard of residual duct flow with a malpositioned device.

We thank Professor Michael Tynan for allowing us to report on a patient under his care.

\section{References}

1 Porstmann W, Wierney L, Warnke H, Gerstberger G, Romanuik PA. Catheter closure of patent ductus arteriosus: 62 cases treated without thoracotomy. Radiol Clin North Am 1971;9:203-18.

2 Rashkind WJ, Cuaso CC. Transcatheter closure of patient ductus arteriosus. Pediatr Cardiol 1979;1:3-8.

3 Rashkind WJ, Mullins CE, Hellenbrand WE, Tait MA. Nonsurgical closure of patent ductus arteriosus: clin-. ical application of the Rashkind PDA occluder system. Circulation 1987;75:583-92.

4 Perry SB, Keane JF, Lock JE. Interventional catheter-을 isation in pediatric congenital and acquired heart음 disease. Am J Cardiol 1987;61 (suppl): 109G-17G.

5 Bash SE, Mullins CE. Insertion of patent ductus $\stackrel{\mathbb{D}}{\circ}$ occluder by transvenous approach: a new technique [Abstract]. Circulation 1984;70 (suppl II):285.

6 Rashkind WJ. Transcatheter treatment of congenital $\vec{O}$ heart disease. Circulation 1983;67:711-6.

7 Dyck JD, Benson LN, Smallhorn JF, McLaughlin PR, Freedom RM, Rowe RD. Catheter occlusion of the persistently patent ductus arteriosus. Am J Cardiol? 1988;62:1089-92. 